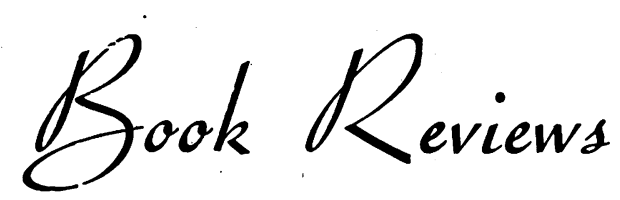

\section{LABORATORY IDENTIFICATION OF PATHOGENIC FUNGI SIMPLIFIED}

By. Elizabeth. L. Hazen, Ph.D., and Frank Curtis Reed. Pp. xii + ro8, with 22 illustrations. Oxford: Blackwell Scientific Publications Ltd. 1955.405.

Mycology is a vast, difficult and incompletely explored field and the experts in it are few. Medical mycology is a small fragment of it, over complicated by repeated changes of nomenclature and by inadequate co-operation between laboratory and clinical workers; few, if any, pathologists in this country are prepared to confine their attention to it. The average pathologist is frightened from the subject altogether by the size of the systematic study or by the pettiness of the purely medical one.

This small book will meet the needs of the bacteriologist who wishes to identify the occasional mould that arrives in his department without laboriously learning a new and difficult language the words of which may change from year to year. It is frankly a picture book with each stage of the development of the mould illustrated.

The excellent photographs are accompanied by brief descriptions of the macroscopic and microscopic characteristics of each organism and of the cultural methods required. There is an appendix giving the formulae of the media mentioned.

The book can be confidently recommended to anyone wishing to identify the pathogenic fungi.

W.H.H.

\section{THE GENESIS AND PREVENTION OF CANCER}

By W. Sampson Handley, M.S., F.R.C.S. New and revised edition. Pp. $x x+320$, with II4 illustrations. London: John Murray. 1955. 2 Is.

The sub-title of this work is significant in underlining the need for constant review of the position in cancer research. Every publication on the subject is a foothold rather than a platform.

The author demonstrates the perfect marriage between the clinician's art and the pathologist's science. His views on the structural aspects of the lymphatic system in the spread of tumours have been widely accepted. His views on the functional significance of lymph stasis in the aetiology of cancer are well established, though less widely accepted.

The book forms a valuable addition to the library of all who treat the disease.

\section{HYPNOSIS IN ASTHMA}

By A. Philip Magonet, B.Sc., M.D., C.M. Ppठ 95. London: Wm. Heinemann Ltd. 1955 7s. $6 \mathrm{~d}$.

This little book puts before the medical professio objective evidence of the value of hypnotherapy asthma. It will cause many practitioners to reviev. their hopeless cases, and those of us who have seen $40 \mathrm{~cm}$. vagotomy scars on ' unimproved ' patientise will appreciate better than most that here, indeeक is a therapy of 'first choice' rather than 'lasp resort.'

\section{SURGICAL PHYSIOLOGY OF THE ADRENAL CORTEX}

By James D. HARDY, M.S.(Chem.), M.D., F.A. Pp. xxi + r9I, with 34 illustrations. Oxfordo Blackwell Scientific Publications. 1955.

This is a most interesting and important book In comparatively few pages the author has manage to present a well-balanced and comprehensive account of current knowledge of the physiological activities of the Adrenal Cortex, and at the sams time, as the title suggests, he has developed his thesis to show the importance of these activities $i \vec{B}$ the response of patients to various forms of stress including Surgery. He demonstrates by a series of carefully planned experiments from his ow practice the metabolic disturbances and physio logical adjustments that occur in patients under going single and multi-stage surgical proceduresand compares these changes with those found in other forms of stress. Consideration is given to the arrangement of the operative schedule in the chronically ill patient and to methods by which his physiological reserves can be assessed.

The upsets occurring as the result of pathologicat changes in the Adrenals themselves also come in fo⿱ discussion, and the author gives an up-to-dates account of the pharmacological effects of adrena hormones and ACTH in clinical medicine generallys

Every surgeon should read this monograph it analyses what happens in his severely ill patients explains how the changes can be predicted, and finally describes how they may be avoided.

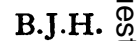

